\title{
Research on the Decent Employment Influencing Factors of the New Generation of Migrant Workers from the Perspective of Human Capital
}

\begin{abstract}
Ruihan Liu, Zichen Zhang and Jing Chen*
Chengdu University of Information Technology, Chengdu, China

*Corresponding author. Email: 749078507@qq.com

ABSTRACT

Realizing decent employment for the new generation of migrant workers can alleviate labor-management conflicts and promote harmonious social development. This paper uses the 2017 database of the Chinese General Social Survey (CGSS) to analyze the relationship between the human capital of the new generation of migrant workers and decent employment. The research shows that: human capital and the realization degree of decent employment are positively correlated. The gender, age, education, health, and labor migration of the new generation of migrant workers have a significant impact on decent employment. The standardized coefficients of age, education, health, and labor migration in the model are $0.131,0.273,0.193,0.460$.It shows that for every increase of age by 1 unit, the realization degree of decent employment increases by 0.131 units; for every unit of academic qualifications, the realization degree of decent employment increases by 0.273 units; for every 1 unit of health status, the realization degree of decent employment increases by 0.193 units; For every increase of 1 unit of labor migration, the realization degree of decent employment increases by 0.460 units.
\end{abstract}

Keywords: The new generation of migrant workers, Human capital, Decent employment

\section{INTRODUCTION}

Employment is the foundation of people's livelihood and the source of wealth. In 2021, the two sessions will focus on "strengthening employment priority policy" and "stabilizing existing jobs", and create more fair employment Opportunity [1]. The younger generation of migrant workers has become the main force in urbanization in the new era. Compared with the older generation of migrant workers, the new generation of migrant workers has higher expectations for themselves and the work they are doing. However, the working environment in the labor market is poor, wage arrears, and employment The psychological gap caused by discrimination and other issues has severely hit the group's enthusiasm for employment, intensified labor conflicts, and may even become a key factor affecting the stable development of society and economy.

In order to solve the various problems that arise in the employment of workers, the International Labour Conference put forward the concept of "decent employment". Decent employment means that workers have enough jobs and income, and their basic labor rights and right to speak are guaranteed. Therefore, based on the 2017 Chinese General Social Survey (CGSS) data, this article discusses the impact of gender, age, education, health and labor migration on decent employment in human capital from the employment status of the new generation of migrant workers, and proposes relevant countermeasures and suggestions.

\section{ANALYSIS OF THE STATUS}

\subsection{Analysis of Current Employment Situation of the New Generation of Migrant Workers}

In April 2021, the National Bureau of Statistics released the employment situation of the first quarter of the country [2]:With the improvement of the epidemic situation, all industries have resumed work and production at a faster pace, the unemployment rate in urban areas has dropped, and the overall employment situation is stable. However, the pressure on total employment remains undiminished, the labor market is structurally unbalanced, and there are still problems such as "difficulty in finding jobs" and "difficulty in 
recruiting workers". In the COVID-19 outbreak, my country's service industry was greatly injured. Some small, medium and micro enterprises are still in the process of recovery, facing difficulties in production and operation, and cannot provide more jobs to meet the employment needs of migrant workers. Compared with the service industry, the coastal industries are engaged in major industries. However, enterprises are facing problems such as difficulty in recruiting first-line ordinary workers, difficult recruiting skilled workers, and difficult recruiting high-skilled talents.

The State Council Information Office in the press conference, and the spokesperson of the National Bureau of Statistics mentioned [3]: In the first quarter of 2021, the number of migrant workers and peasants was approximately 170 million, a decrease of 2.46 million from the same period in 2019. The unemployment rate in March reached 5.4\%, compared with the same period in 2019. An increase of $0.1 \%$ in February. Restricted by their own human capital and urban employment policies, facing unemployment, in the effective sample data, $48.8 \%$ of migrant workers still rely on social networks, entrusting relatives and friends to introduce jobs, 26.8\% of new-generation migrant workers' unions participate in job fairs, and $17.1 \%$ The new generation of peasant labor unions search for job opportunities through the Internet and other media platforms. $7.3 \%$ of the new generation of peasant workers choose employment agencies to register for jobs (Figure 1). Without a job, it is impossible to have the right to work, let alone decent employment. Therefore, to promote the employment of the new generation of migrant workers, it is necessary to broaden the employment channels and make precise efforts on both sides of the labor supply and demand, so as to improve the matching degree of labor quality and corporate job demand.

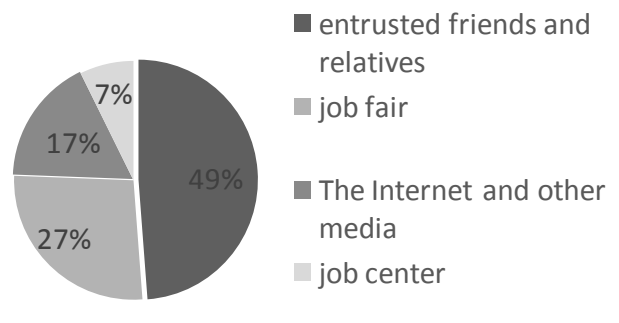

Figure 1. The proportion of employment channels.

\subsection{Analysis of the Situation of Rights Protection}

The new generation of migrant workers work in cities, which promotes the development of urban economy, but the labor rights and interests of this group are infringed due to their special status and marginal status. Labor contracts are an important guarantee for workers to realize their labor rights. The valid sample data in Table1 show that $62.1 \%$ of the new generation of migrant workers have not signed labor contracts with their employers, and $44.6 \%$ of the 336 new generation of migrant workers who signed labor contracts have a contract term of less than one year. $66.7 \%$ of the 951 new generation migrant workers working more than 44 hours a week, of which $26.5 \%$ work more than 11 hours a day; Most of the social protection models for migrant workers adopt the practice of establishing a separate social security system for migrant workers, with social insurance as the main content [4]. But in fact, migrant workers affected by their own quality, age, and employment situation, and their overall coverage is not ideal, especially the endowment insurance and industrial injury insurance coverage is low. In addition, under the influence of macro-factors of unbalanced economic development in urban and rural areas and micro-factors of going out to earn money to support a family and seeking personal development, the rural population's mobility has accelerated, and there have been transfers and surrenders of insurance.

Table 1. Labor contracts and working hours

\begin{tabular}{|l|l|l|}
\hline The problem & Options & Percentage \\
\hline Whether to sign a labor & Yes & $32.9 \%$ \\
contract & No & $62.1 \%$ \\
\hline \multirow{3}{*}{ Contract Period } & $<1$ year & $44.6 \%$ \\
& $1-3$ years & $41.7 \%$ \\
\hline Whether working hours & $>3$ years & $13.7 \%$ \\
exceed 44 hours per week & No & $66.7 \%$ \\
\hline Average working hours per & $<9$ hours & $33.3 \%$ \\
day & $9-11$ hours & $19.7 \%$ \\
& $>11$ hours & $26.5 \%$ \\
\hline
\end{tabular}

\subsection{Analysis of the Current Situation of Rights and Interests Appeal}

The appeal for rights and interests is more intense, but the channel of appeal is blocked. The life goal of the new generation of migrant workers is changing from earning money to integrating into urban life. They urgently hope that their rights and interests in employment, housing, children's education, medical care and pension can be fully protected. According to the Monitoring Report of Migrant-Workers in 2019[5], $27.6 \%$ of migrant workers in cities have participated in activities organized by community organizations, $13.4 \%$ have joined trade unions, and $84.2 \%$ of the farmers who have joined trade unions have participated in trade union activities, indicating that the degree of organization of migrant workers has improved, but the overall situation is still not optimistic. 
Table 2. Participation in Organizational Activities

\begin{tabular}{|l|l|l|}
\hline The problem & Options & Percentage \\
\hline Whether to join a labor & Yes & $4.10 \%$ \\
union & No & $95.9 \%$ \\
\hline Whether to participate in & Yes & $3.40 \%$ \\
group political activities & No & $96.6 \%$ \\
\hline
\end{tabular}

Table 2 show the CGSS in 2017 valid sample data in new generation migrant workers group activity: only $4.1 \%$ of the new generation of migrant workers to join labor union, the vast majority of migrant workers have not received the union's help, $96.6 \%$ of the new generation of migrant workers group have not participated in group political activities. It will be very hard for migrant workers to defend their rights.

\section{MATH AND EQUATIONS}

\subsection{Research Hypothesis}

Human capital investment activities to improve the productive capacity of workers include five aspects: health activities, training, migration, formal education and informal education. In the process of labor, the new generation of migrant workers, due to age and gender differences, their own educational level and Different levels of health lead to differences in employment industries and employment organizations, as well as differences in employment opportunities, work income, labor contract signing, and union membership. In view of this, this paper proposes five hypotheses on the mechanism of human capital influencing the decent employment of the new generation of migrant workers.

H1: Gender has a significant impact on the realization degree of decent employment for the new generation of migrant workers.

$\mathrm{H} 2$ : Age has a significant impact on the realization degree of decent employment for the new generation of migrant workers.

H3: Education has a significant positive impact on the realization degree of decent employment for the new generation of migrant workers.

H4: Health has a significant positive impact on the realization degree of decent employment for the new generation of migrant workers.

H5: Labor migration has a significant positive impact on the realization degree of decent employment for the new generation of migrant workers.

\subsection{Model Setting}

This article uses a multivariate linear model to study the impact of human capital on decent employment. "Y" represents decent employment, including five variables: labor contract, social insurance, social dialogue, equal employment and work income." $X$ " represents the independent variables, including 5 variables : gender, age, education, health and labor migration. " $\theta \mathrm{i}$ " is the regression constant term, " $\beta 1$ ", " $\beta 2$ " and " $\beta 3$ " represent the standardized regression coefficient of the variable, and " $i$ " is the error disturbance term. The specific model is as follows:

$\mathbf{Y}=\left[\begin{array}{l}Y_{1} \\ Y_{2} \\ \vdots \\ Y_{n}\end{array}\right] \quad \mathbf{X}=\left[\begin{array}{l}X_{1} \\ \vdots \\ X_{\mathrm{n}}\end{array}\right] \quad \boldsymbol{\beta}=\left[\begin{array}{l}\theta_{\mathrm{i}} \\ \beta_{1} \\ \vdots \\ \beta_{n}\end{array}\right] \quad \boldsymbol{\varepsilon}_{\mathbf{i}}=\left[\begin{array}{l}\varepsilon_{1} \\ \vdots \\ \varepsilon_{n}\end{array}\right]$

The matrix expression is:

$\mathrm{Y}=\beta \mathrm{X}+\varepsilon=\theta \mathrm{i}+\beta 1 \mathrm{X} 1+\beta 2 \mathrm{X} 2+\ldots+\beta \mathrm{n} \mathrm{Xn}+\varepsilon \mathrm{i}$

\section{RESEARCH HYPOTHESIS AND MODEL SETTING}

\subsection{Data Sources}

The data in this paper came from the database of Chinese General Social Survey (CGSS) in 2017. In order to get the data of this study, we have selected those who were born after 1980, have an agricultural hukou and are engaged in non-agricultural work (including currently engaged in non-agricultural work, previously engaged in non-agricultural work but currently unemployed, previously engaged in non-agricultural work but currently engaged in agriculture), after removing the missing value samples, a total of 1158 valid samples.

\subsection{Sample Description}

Table 3. Descriptive statistics of samples.

\begin{tabular}{|l|l|l|}
\hline Category & Options & $\begin{array}{l}\text { Proportio } \\
\text { n }\end{array}$ \\
\hline \multirow{4}{*}{ Gender } & Women & $46.5 \%$ \\
& Men & $53.5 \%$ \\
& Age 24 and below & $2.8 \%$ \\
& $25 \sim 30$ years old & $23.6 \%$ \\
& $31 \sim 36$ years old & $35.7 \%$ \\
& $37 \sim 41$ years old & $38.0 \%$ \\
\hline \multirow{5}{*}{ Education } & Primary school and below & $12.4 \%$ \\
& Junior high school & $40.2 \%$ \\
& Technical school & $7.8 \%$ \\
& High school & $17.5 \%$ \\
& Junior college & $11.4 \%$ \\
& Bachelor degree and above & $10.7 \%$ \\
Health & Unhealthy & $4.5 \%$ \\
& General & $18.6 \%$ \\
Labor & Health & $76.9 \%$ \\
migration & Migration & $58.8 \%$ \\
& Not migration & $41.2 \%$ \\
\hline
\end{tabular}


Table 3 shows the descriptive statistics of human capital of CGSS valid samples. Female migrant workers accounted for $46.5 \%$ and male workers $53.5 \%$; There are 32 new generation migrant workers under the age of 24 , accounting for only $2.8 \%$. Nearly $60 \%$ of the new generation of migrant workers are between 25-36 years old, and the new generation migrant workers aged 36-41 account for 440 people, accounting for Than $38 \%$. It can be found that the age of the new generation of migrant workers is gradually increasing, but in general they are in the age of pursuing careers and struggling. The new generation of migrant workers mainly focus on junior high school, accounting for $40.2 \%$, and a total of 256 people or above junior college, accounting for $22.1 \%$. It can be seen that the overall educational level of the new generation of migrant workers has risen, but it is still low. As one of the main components of human capital, health is the basis and key to the formation of human capital. About $80 \%$ of the new generation of migrant workers think they are in good health. To some extent, labor migration can make labor resources flow reasonably. About $60 \%$ of the new generation of migrant workers have migrated.

\subsection{Empirical Analysis}

In order to further understand the impact of human capital on decent employment, a regression model was established, and multiple linear regression analysis was conducted according to the types of dependent variables. The values of adjusted $\mathrm{R}$ square in Table 4 indicate that human capital factors can explain $25.5 \%$ of the realization degree of decent employment, and the model fit is acceptable. The expansion factor (VIF) of each factor in the collinearity statistics of the model is all less than 5, indicating that there is no multicollinearity in the independent variables included in the model.

Under the condition of controlling for other variables, the gender unstandardized coefficient in the model is $-0.310, \quad \mathrm{P}<0.01$, indicating that gender significantly affects decent employment, and the realization degree of decent employment for women is 0.310 units lower than that for men. Hypothesis $\mathrm{H} 1$ is verified.; The age unstandardized coefficient in the model is $0.131, \mathrm{P}<0.01$, which indicates that age significantly positively affects the decent employment. For every increase in age by 1 unit, the realization degree of decent employment increases by 0.131 units. Hypothesis $\mathrm{H} 2$ is verified. However, after taking the work of the new generation of farmers aged 24 and below as the reference category, it is found that as age increases, the realization degree of decent employment has declined; The unstandardized coefficient of education is $0.218, \mathrm{P}<0.01$, indicating that education has a significant positive impact on decent employment. The realization degree of decent employment increases by 0.273 units for each unit of educational background increased. Hypothesis H3 is verified.; The unstandardized coefficient of health is $0.193, \mathrm{P}<0.01$, indicating that health has a significant positive impact on decent employment. For every 1 unit of health increase, the realization degree of decent employment increases by 0.193 units. Hypothesis $\mathrm{H} 4$ is verified.; The unstandardized coefficient of labor migration is 0.460 $(\mathrm{P}<0.01)$, indicating that labor migration has a significant positive impact on decent employment, and the realization degree of decent employment in groups with labor migration is 0.460 units higher than that in groups without labor migration. Hypothesis $\mathrm{H} 5$ is verified.

Table 4. Multiple regression analysis of human capital on the realization degree of decent employment

\begin{tabular}{|c|c|c|c|c|c|c|c|}
\hline \multirow[t]{2}{*}{$\begin{array}{l}\text { Model: } \\
\text { Decent job }\end{array}$} & \multicolumn{2}{|c|}{\begin{tabular}{|c|}
$\begin{array}{c}\text { Unstandardized } \\
\text { coefficient }\end{array}$ \\
Standard
\end{tabular}} & \multirow{2}{*}{$\begin{array}{c}\begin{array}{c}\text { Standardized } \\
\text { coefficient }\end{array} \\
\text { Beta }\end{array}$} & \multirow[t]{2}{*}{$\mathrm{T}$} & \multirow[t]{2}{*}{ Sig. } & \multicolumn{2}{|c|}{ Collinearity Statistics } \\
\hline & B & & & & & Tolerance & VIF \\
\hline Constant & 0.645 & 0.193 & & 3.340 & $0.001 * * *$ & & \\
\hline Gender & -0.310 & 0.054 & -0.145 & -5.628 & $0.000 * * *$ & 0.994 & 1.006 \\
\hline Age & 0.131 & 0.033 & 0.109 & 4.036 & $0.000 * * *$ & 0.881 & 1.135 \\
\hline Age $(<24)$ & 0 & & & & & & \\
\hline Age(24-30) & 0.670 & 0.154 & 0.282 & 4.353 & $0.000^{* * *}$ & & \\
\hline Age(31-36) & 0.516 & 0.152 & 0.231 & 3.405 & $0.001 * * *$ & & \\
\hline Age(37-41) & 0.371 & 0.153 & 0.163 & 2.434 & $0.015^{* *}$ & & \\
\hline Education & 0.273 & 0.019 & 0.396 & 14.216 & $0.000 * * *$ & 0.833 & 1.201 \\
\hline Health & 0.193 & 0.051 & 0.098 & 3.780 & $0.000 * * *$ & 0.970 & 1.030 \\
\hline Migrated & 0.460 & 0.057 & 0.212 & 8.107 & $0.000 * * *$ & 0.943 & 1.060 \\
\hline The $\mathrm{F}$ value & & & & $78.995^{5}$ & & & \\
\hline $\begin{array}{l}\text { Adjusted } \\
\text { R squared }\end{array}$ & & & & 0.255 & & & \\
\hline DW value & & & & 1.695 & & & \\
\hline
\end{tabular}




\section{RESEARCH CONCLUSIONS AND COUNTERMEASURES}

\subsection{Research Conclusions}

Through the above research, this paper mainly draws the following conclusions: (1) Gender factors have a significant impact on the the realization degree of decent employment of migrant workers. There are significant differences among the new generation of migrant workers of different genders. The realization of decent employment of new generation of male migrant workers is generally higher than that of female. (2) Age has a significant impact on the realization degree of decent employment for the new generation of migrant workers, but the realization degree of decent employment decreased with the increase of age. (3) The new generation of migrant workers who are physically and mentally healthy and highly educated have achieved a high degree of decent employment.(4) Labor migration factors have a significant impact on the realization degree of decent employment of the new generation of migrant workers, but the number of migrations should remain moderate.

\subsection{Suggestions}

The improvement of labor quality formed by human capital investment brings direct benefits such as improving employment conditions and increasing employment income. For the whole society, the accumulation of human capital formed by investment promotes the long-term sustainable development of social economy. Therefore, on the basis of the above research conclusions, this paper clarifying the main responsibilities of the government, enterprises and the new generation of migrant workers, and further exploring the countermeasures and suggestions to help the new generation of migrant workers better achieve decent employment.

First, it ought to give full play to the role of employment policy support. The government can start from two aspects: first, to stabilize the current positions of migrant workers, expand the scope of benefits of the stabilization policy, and give certain fiscal and financial policy support to small, medium and micro enterprises and new agricultural operating entities; Followed by broadening the employment channels and comprehensively improving the quality of employment services, due to the existing in the labor market information asymmetry phenomenon, the new generation of migrant workers looking for work is affected by the employment situation and their own labor quality limit, available resources is not much. At this time, the government should give full play to its public service functions to do a good job in the release of employment information, registration of the unemployed, and entrepreneurship to promote employment, so as to create more fair employment opportunities for this new generation of migrant workers.

Second, it ought to enhance learning awareness. Whether it is formal education or informal education, it is necessary to cultivate internal learning motivation and learning awareness. The new generation of migrant workers enter the city to work after completing their junior or senior high school. Most of them lack farming experience, but their use and acceptance of the Internet are better than the older generation of migrant workers. Therefore, in addition to making efforts in formal education, the government should establish a tripartite vocational training base for the government, enterprises, and migrant workers, carry out various forms of learning activities, and encourage the group to use a variety of online learning platforms and learning applications to learn independently. With the help of TV networks, propaganda slogans, and radio to promote the meaning of lifelong learning, a good learning atmosphere is formed. Only by continuously learning and accumulating a wide range of knowledge and vocational skills can we better respond to environmental changes, help transfer knowledge and skills to other work environments, and enhance our employability [6], and not be eliminated by the torrent of the times.

Third, it ought to give full attention to investment in health care. Health has a significant effect on non-agricultural employment. To increase the stock of health capital, it is necessary to build a major government-led and enterprise-assisted mechanism, strengthen the public health service system, and play the role of social security; The enterprises focus on the prevention and control of occupational hazards to invest in the health of the new generation of migrant workers, through monetary and non-monetary forms, including providing healthy nutritious meals and health subsidies, timely updating wearable equipment, conducting health assessments, and Employees Assistance Programs(EPA), safety and health knowledge lectures, etc.

Fourth, according to the different situations of the new generation of migrant workers "staying in the city" and "returning to their hometown", the government promotes labor migration and investment, and enhances the new generation of migrant workers' ability to accumulate human capital, career choice and employment, and urban development integration. For the new generation of migrant workers who want to stay in the city, it is necessary to promote the citizenization of migrant workers and solve the problem of unequalization of public services behind the urban-rural household registration system to ensure that the new generation of migrant workers enjoy the same treatment as urban residents in terms of employment, social security, and housing. For the new generation of 
migrant workers returning to the countryside, the government can carry out various activities such as entrepreneurship education, entrepreneurship training, and entrepreneurship publicity. It can also optimize the entrepreneurial environment and improve the entrepreneurial system to help return migrant workers to give full play to their entrepreneurial advantages.

Fifth, enterprises and the new generation of migrant workers establish stable labor relations with rights and responsibilities, play a formal organizational role, and rationally use private power to help protect their rights. The new generation of migrant workers has a low level of education and lack of legal knowledge. The dual identities of farmers and workers and the seasonal characteristics of agricultural production activities determine that this group has less free time and scattered time for migrant workers. Therefore, when rights and interests are damaged, either do not know how to use legal weapons to protect themselves, or they give up seeking help from a formal organization due to lack of labor contracts, high cost of litigation, long time, and low efficiency. First of all, local governments have made efforts to supervise the signing and performance of labor contracts with new generations of migrant workers in accordance with the law; secondly, the All-China Federation of Trade Unions should adopt different methods for different types of enterprises, assist enterprises to cultivate and develop trade union organizations, and help migrant workers solve various practical issues; Finally, the labor market builds an employment assistance system that focuses on public relief and rights protection, supplemented by private relief and rights protection, including collective consultation and rights protection, letters and visits, elderly assistance to petition for rights protection [7],
Internet rights protection and other private rights protection methods.

\section{REFERENCES}

[1] Government Work Report in 2021 (EB/OL)], 2021. DOI:http://www.gov.cn/xinwen/2021-03/19/content _5590441.html

[2] National Bureau of Statics, Zhang Yi: Employment Situation Stable in the First Quarter (EB/OL), 2021, DOI:http://wap.stats.gov.cn/jd/20210416_1816435. html

[3] The State Council Information Office in the press conference on the Situation of National Economy in the First Quarter (EB/OL), 2021. DIO:http://www.scio.gov.cn/m/xwfbh/xwbfbh/wqf bh/44687/45283/index.htm

[4] Lixiong Yang, Research on the Social Protection of Migrant Workers [J], Journal of Renmin University of China, 2006 (6): 24-25

[5] National Bureau of Statistics "2019 Migrant Workers Monitoring Survey Report (EB/OL)",2020. DIO:http://www.stats.gov.cn/tjsj/zxfb/202004/t202 00430_1742724.html

[6] Wenchen Guo, Yannan Duan., Research on New Career and Human Resource Management Practice Based on the Perspective of Challenge and Change [J]. Journal of Management, 2013, 10 (12): 1785-1791.

[7] Yongguang Ouyang, Research on Private Relief in Construction Migrant Workers' Rights Protection [D]. Huazhong University of Science and Technology, 2019. 